\title{
A comparative study of early vs. delayed laparoscopic cholecystectomy in acute cholecystitis
}

\author{
Yadav RP ${ }^{1}$, Adhikary $\mathbf{S}^{1}$, Agrawal CS ${ }^{1}$, Bhattarai B ${ }^{2}$, Gupta RK ${ }^{1}$, Ghimire A $^{2}$ \\ ${ }^{1}$ Department of Surgery, ${ }^{2}$ Department of Anesthesia and Critical Care, B.P. Koirala Institute of Health Sciences
}

\begin{abstract}
Aims and Objectives: To compare the outcome in early vs. delayed laparoscopic cholecystectomy in terms of frequency of intra-operative and postoperative complications and to determine the rate and reasons for conversion.

Materials and methods: A prospective randomized clinical trial was performed in the Department of Surgery at BP Koirala Institute of Health Sciences from February 2003 to June 2004 in all patients with the diagnosis of acute calculus cholecystitis.

Results: Out of 145 cases, 50 cases were included in our study where 12 (24\%) patients were males and 38 (76\%) were females (M:F=1:3.16). The mean (SD) age of patients in early and delayed groups were 42.68 yrs. (14.18) and 40.26 yrs. (11.62) respectively. The mean (SD) duration of symptoms in early successful and converted groups were 109.24 hrs. (43.66) and 132 hrs. (49.96) respectively and the mean (SD) duration of symptoms in delayed successful and converted groups were 15.36 months (13.88) and 41 months (40.73) respectively. In early group, 17 (68\%) patients had total leukocyte count more than $10,000 / \mathrm{cmm}$ and they had ultrasound findings suggestive of acute cholecystitis. Out of 25 patients in early group, seven had jaundice and ten had deranged liver function in the preoperative period. In early group $4(16 \%)$ patients; and in delayed group $3(12 \%)$ had to be converted to open cholecystectomy $(\mathrm{P}=1.00)$. In early group $10(40 \%)$ and in delayed $5(20 \%)$ cases had intra-operative complications $(\mathrm{P}=0.122)$. The total hospital stay was longer in the delayed group. The postoperative hospital stay in early and delayed converted groups were higher than early and delayed successful group $(\mathrm{P}=0.081, \mathrm{P}=0.082)$.
\end{abstract}

Conclusion: Both early and delayed laparoscopic cholecystectomy is possible and safe in the treatment of acute cholecystitis.

Key words: Acute cholecystitis, Laparoscopic cholecystectomy, Conversion

$\mathrm{M}$ anagement of gallstones has changed gradually over two decades with Laparoscopic Cholecystectomy (LC) emerging as the gold standard for the elective treatment of symptomatic gallstones. Considerable amount of experience acquired by several centres with laparoscopic techniques have led surgeons world over to attempt this approach for acute cholecystitis $^{1,2}$. However, the precise role as well as the potential benefits of Laparoscopic Cholecystectomy in the treatment of acutely inflamed gallbladder has not been clearly established and continue to be controversial. We conducted this study to find out what is safe for acute cholecystitis patients.

\section{Materials and methods}

The study was performed in the Department of Surgery at BP Koirala Institute of Health Sciences from February 2003 to June 2004. Fifty patients of either sex diagnosed to have acute calculus cholecystitis presenting within seven days after the onset of pain were included in our study. Patients presenting with acute cholecystitis more than seven days duration, those having common bile duct stones or ductal dilatation, patients with significant medical disease that rendered them unfit for laparoscopic surgery and patients, who refused to undergo laparoscopic surgery were excluded.

A combination of clinical, ultrasonographic, and laboratory criteria established the diagnosis of acute cholecystitis. Clinical criteria included at least three of the following: right upper quadrant pain, Murphy's sign, tenderness in the right hypochondrium, local signs of peritonitis, and fever (temperature $>100^{\circ} \mathrm{F}$ ).

After informed consent, patients with acute cholecystitis were randomized into early or delayed operation using closed envelope method. Patients in the delayed group were managed with intravenous fluids, antibiotics

Correspondence

Rohit Prasad Yadav

Assistant Professor, Department of Surgery,

B.P. Koirala Institute of Health Sciences

E-mail: yadavrohit@yahoo.com 
(injection Cefuroxime and injection Metronidazole) and injection Diclofenac sodium for two days followed by oral antibiotics and analgesics for the next five days. They were discharged from our hospital after a complete relief of symptoms and were called for laparoscopic cholecystectomy after six to eight weeks. Similarly, patients in early group were managed with intravenous fluids, antibiotics (injection Cefuroxime and injection Metronidazole) injection Tramadol in postoperative period. They were posted for laparoscopic cholecystectomy in routine operation theatre as soon as possible. Standard four ports Laparoscopic cholecystectomy under general anaesthesia using carbon dioxide for pneumoperitoneum was performed in either group by the same consultant. No topical LA (Sensorcaine) was given at port site post operatively.

Any intraoperative complications like rupture or perforation of gall bladder, difficulty in dissection, spillage of stones, common bile duct injury and other visceral injury were noted in both the groups. The resected gallbladder was removed through umbilical port and sent for histopathological examination.

Patients who were operated successfully with laparoscopic method and those who were converted to open method were termed as early successful and early converted groups. Similarly, in delayed group they were divided in delayed successful and delayed converted groups.

Intra-muscular Tramadol was injected on demand after operation. Time of demand of first dose of analgesia and the total amount of analgesics required in the first $24 \mathrm{hrs}$ were noted. Postoperative pain was assessed by Visual Analog Scale (VAS) at six hrs, $12 \mathrm{hrs,} \mathrm{24hrs}$ and $48 \mathrm{hrs}$ in both groups of patients. Postoperative complications and total duration of hospital stay were recorded. Follow up of patients was carried out at one month, six months and 12 months. All the data obtained were entered into the database and analysis was made by Statistical Package for Social Sciences (SPSS) using appropriate statistical tests.

\section{Results}

Out of 145 cases, 50 cases were included and randomized into early and delayed laparoscopic cholecystectomy groups consisting of 25 cases in each group. There were 12 males and 38 females. The overall sex ratio M:F was 1:3.16. The mean (SD) duration of symptoms in early successful and converted groups were $109.24 \mathrm{hrs}$ (43.66) and $132 \mathrm{hrs}$ (49.96) respectively which was not statistically significant $(\mathrm{P}=0.359)$.

In preoperative period, six patients had jaundice in the early successful group and one patient had jaundice (total bilirubin $>2 \mathrm{mg} / \mathrm{dl}$ ) in converted group. Ten patients in early successful group and two patients in early converted group had mildly deranged liver enzymes in preoperative period.

The mean (SD) of number of acute attacks in our study subjects in early and delayed successful groups were: $1.57(0.75)$ and $1.68(1.13)$ respectively which were comparable in both the groups $(\mathrm{P}=0.709)$. The mean (SD) number of attacks in early converted and delayed converted groups were: 3(0.82) and $1(0.00)$ respectively ( $\mathrm{P}=0.009)$.

The mean (SD) operating time in early successful and converted groups were: 94.76 mins (35.79) and 176.25 mins (52.50) which was statistically significant $(\mathrm{P}=0.001)$. Similarly, the mean (SD) operating time in delayed successful and delayed converted groups were: 61.67 mins (18.76) and 186.67 mins (86.07) respectively which was also statistically significant $(\mathrm{P}=0.000)$.

The number of patients in early and delayed converted groups were $4(16 \%)$ and $3(12 \%)$ respectively $(\mathrm{P}=1.00)$. The reasons for conversion to open cholecystectomy are shown in Table 1.

There were $10(40 \%)$ cases in early group and $5(20 \%)$ cases in delayed group who had intraoperative complications $\quad(\mathrm{P}=0.122)$. The intraoperative complications were tear of gallbladder and spillage of stones, perforation of gallbladder, bleeding from gallbladder fossa, cardiac arrythmia, clip left inside the peritoneal cavity and sinus bradycardia.

Six cases in early group and ten in the delayed group developed postoperative complications $(\mathrm{P}=0.041)$. The complications were: postoperative pyrexia, fever, bile leak and retained common bile duct stone. After the completion of operation, severity of pain in all cases was assessed by Visual Analog Scale (VAS) and the results tabulated (table 2). Statistical analysis also showed that there were no difference in severity of pain between the early successful group and delayed successful group at $6 \mathrm{hrs}, 12 \mathrm{hrs}, 24 \mathrm{hrs}, 48 \mathrm{hrs}$ and in the requirement of injection tramadol. Similarly there were no differences in the severity of pain between early converted and delayed converted groups.

The total hospital stay in early and delayed successful groups were: 4.33 days (1.46) and 7.23 days (1.63) respectively $(\mathrm{P}=0.000)$ (Figure 1 ).

The resected specimen of gall bladder showed following pathological diagnosis: 11(44\%) patients had acute cholecystitis, $10(40 \%)$ acute on chronic cholecystitis, $3(12 \%)$ acute and diffuse gangrenous cholecystitis, and $1(4 \%)$ chronic cholecystitis with congestion. 
One patient developed jaundice after two weeks of operation (early converted group) which was found to be due to common bile duct stones and was managed by Endoscopic Sphincterotomy.

Table 1: Reasons for Conversion to Open in Early and Delayed Groups

\begin{tabular}{|l|c|c|c|}
\hline \multicolumn{1}{|c|}{ Reasons } & $\begin{array}{c}\text { Early group } \\
(\mathbf{n = 4})\end{array}$ & $\begin{array}{c}\text { Delayed group } \\
(\mathbf{n = 3})\end{array}$ & Total \\
\hline Frozen calot's triangle & 3 & 1 & 4 \\
\hline Difficult anatomy and gallbladder perforation & 0 & 1 & 1 \\
\hline Difficult anatomy and distended stomach & 1 & 0 & 1 \\
\hline Tear of cystic duct near common bile duct & 0 & 1 & 1 \\
\hline Total & 4 & 3 & 7 \\
\hline
\end{tabular}

Table 2: Early successful group Vs Delayed successful groups

\begin{tabular}{|l|c|c|c|c|c|}
\hline & \multicolumn{2}{|c|}{$\begin{array}{c}\text { Early successful group } \\
(\mathbf{n}=\mathbf{2 1})\end{array}$} & \multicolumn{2}{c|}{$\begin{array}{c}\text { Delayed successful } \\
\text { group (n=22) }\end{array}$} & P Value \\
\hline Successful groups & Mean & \pm SD & Mean & \pm SD & \\
\hline $6 \mathrm{hrs}$ & 6.62 & 1.32 & 6.77 & 1.23 & 0.695 \\
\hline $12 \mathrm{hrs}$ & 4.95 & 1.12 & 4.91 & 0.92 & 0.890 \\
\hline $24 \mathrm{hrs}$ & 3.38 & 1.43 & 3.00 & 1.35 & 0.373 \\
\hline $48 \mathrm{hrs}$ & 2.14 & 0.96 & 2.09 & 0.92 & 0.857 \\
\hline Injection tramadol (no. of doses) & 2.43 & 1.03 & 2.18 & 1.01 & 0.431 \\
\hline
\end{tabular}

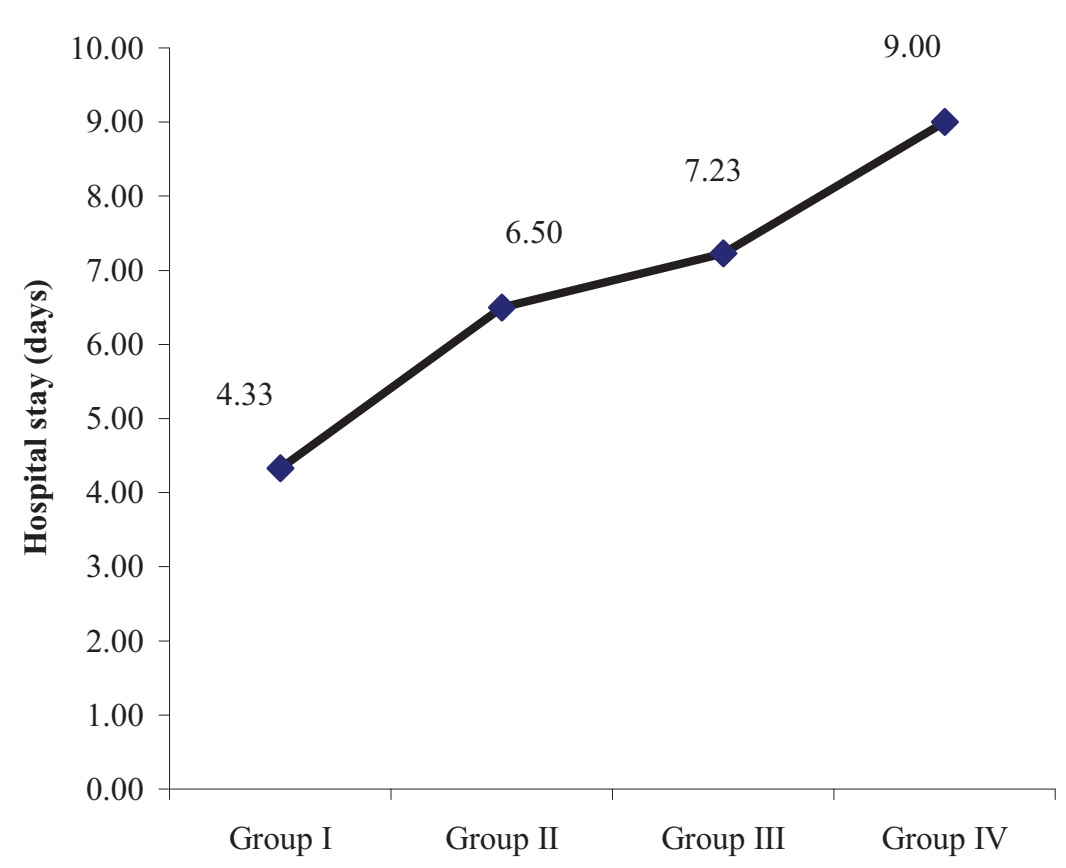

Group I Early successful group

Group II Early converted group

Group III Delayed successful group

Group IV Delayed converted group

Fig 1: Total Hospital Stay (Days) 


\section{Discussion}

In our study population, there were $12(24 \%)$ males and $38(76 \%)$ females. The overall sex ratio M:F was $1: 3.16$ which is slightly more in females as compared to the study done by Holzbach, which showed gallstones to be twice as common in females than males ${ }^{3}$. The rate is higher in our study possibly due to sedentary life style, consumption of diet high in fat content and prevalence of the disease in our country in addition to other factors.

The mean (SD) duration of symptoms in early successful and converted groups were $109.24 \mathrm{hrs}$ (43.66) and 132 hrs (49.96) respectively $(\mathrm{P}=0.359)$. There are prospective randomized studies ${ }^{4,5}$ which demonstrated that the outcome for patients undergoing early open cholecystectomy within 7 days of onset of symptoms was superior to delayed interval surgery. However, A study demonstrated that early laparoscopic cholecystectomy within 4 days minimized surgical complications and increased the chances of a successful laparoscopic approach $^{6}$. Another study revealed that delay in performing an urgent laparoscopic cholecystectomy beyond 96 hours did not affect the operating time or postoperative stay but significantly increased the total hospital stay?

Ten patients in early successful group and two patients in early converted group had mildly deranged liver enzymes. Seven patients had mild jaundice in early group but none of them had stones in the common bile duct. It has been documented that jaundice when present may at times be due to common duct stones, cholangitis, or partial compression of the common hepatic duct by inflammatory oedema caused by impaction of gallstone in Hartmann's pouch (Mirizzi syndrome type- I) ${ }^{8}$.

The mean (SD) operating time in early successful group and delayed successful group in our study were $94.76 \mathrm{~min}$ (35.79) and 61. $67 \mathrm{~min}$ (18.76) respectively $(\mathrm{P}=0.000)$ which were shorter than a similar study done by Lai PBS et $\mathrm{al}^{9}$. In our study and in their study as well, the operating time was significantly higher in early group than delayed group. This can be explained because of inflammation, oedema, bleeding and thick gall bladder with adhesions often makes dissection difficult and bloody which leads to a longer operative time.

In our study, the number of patients in early and delayed converted groups were $4(16 \%)$ and $3(12 \%)$ respectively $(\mathrm{P}=1.00)$. The high rate of conversion in our study could be due to the learning curve which is associated with this procedure, more frequent attacks of acute cholecystitis, difficult anatomy etc. There are studies which have shown conversion rate to be as high as $35 \%$ as was reported by Rattner, Zucker and Kum in their studies ${ }^{1,2,10}$. Asoglu $\mathrm{O}$ et al ${ }^{11}$ showed conversion rates of $4.3 \%$ (7/162) in early group and $2.4 \%$ (24/996) in delayed group. In our study frequent attacks of acute cholecystitis led to increased risk of conversion and the reasons for conversion in early group were frozen calot's triangle, difficult anatomy with distended stomach. In the delayed group, reasons for conversion were: frozen calot's triangle, difficult anatomy and gallbladder perforation and perforation of cystic duct near common bile duct. A study done by Suter M and Meyer A ${ }^{12}$ found the causes of conversion to be inflammation, uncertainty about the anatomy, haemorrhage, suspicion of common bile duct stones, intrahepatic bile ducts not seen at intraoperative cholangiography, primary conversion before attempts at laparoscopic dissection, lesion of common bile duct, colon perforation caused by first trocar, gallbladder perforation with stone dissemination, suspicion of gallbladder cancer ${ }^{12}$.

In a study ${ }^{13}$ it was observed that intraoperative complications were in $24(24 / 159)$ cases. They were perforation of gallbladder (16 cases), bleeding ( 4 cases), perforation of transverse colon (2 cases) and atrial fibrillation (1 case). It was similar to our series except the fact that in their study complications also occurred to adjoining structures like colon.

In an important study ${ }^{12}$ carried out with the use of laparoscopic cholecystectomy for acute cholecystitis showed the following complications: lesion of the common bile duct, postoperative bile leak, retained common bile duct stones, postoperative haemorrhage, pancreatitis, section of right branch of hepatic artery, unexplained transient postoperative jaundice, intraabdominal collection, wound infection and other general complications. In our study six cases in early and one case in delayed group developed postoperative complications. i.e., postoperative pyrexia, fever, bile leak and retained common bile duct stone.

In our study, severity of postoperative pain at $6 \mathrm{hrs}$, $12 \mathrm{hrs}, 24 \mathrm{hrs}, 48 \mathrm{hrs}$ and requirement of injection tramadol were higher in the early converted rather than early successful group. Similarly frequency of injection tramadol required was significantly higher in delayed converted as compared to delayed successful group. Severe pain and frequent administration of injection tramadol required in early group might have been due to the inflammatory changes of acute cholecystitis. Statistical analysis also showed that there were no difference in severity of pain between the early successful group and delayed successful group of patients at $6 \mathrm{hrs}$, 12hrs, 24hrs, 48hrs and injection tramadol. $(\mathrm{P}=0.695$, $\mathrm{P}=0.890, \mathrm{P}=0.373, \mathrm{P}=0.857$, and $\mathrm{P}=0.431$ ) Table 2 . Similarly there were no differences in severity of pain between early converted and delayed converted groups $(\mathrm{P}=0.677, \mathrm{P}=0.211, \mathrm{P}=0.537, \mathrm{P}=0.702$ and $\mathrm{P}=0.704)$. 
In our study the total hospital stay (mean) (SD) in early and delayed successful groups were 4.33 days (1.46) and 7.23 days (1.63) respectively $(\mathrm{P}=0.000)$ Fig 1 . Lai et $\mathrm{al}^{10}$ found shorter total hospital stay in early group (7.6 vs. 11.6 days, $\mathrm{P}<0.001$ ).

\section{Conclusions}

Both early and delayed laparoscopic cholecystectomy is possible and safe in the treatment of acute cholecystitis. Early laparoscopic cholecystectomy offers definitive treatment during the same hospital admission and avoids problems of a failed conservative treatment, delayed surgery and an ugly scar. Furthermore, a reduction in the total hospital stay may be a major economic benefit to the patients of a poor country.

\section{Acknowledgement}

We appreciate Professor Om Prakash Pathania and Mr. Binod Samsohang for preparing this paper.

\section{References}

1. Rattner DW, Ferguson C, Warshaw AL. Factors associated with successful laparoscopic cholecystectomy for acute cholecystitis. Ann Surg 1993; 217:233-7.

2. Zucker KA, Flowers JL, Bailey RW, Graham SM, Buell J, Lambembo AL. Laparoscopic management of acute cholecystitis. Am J Surg 1993; 165:508-14.

3. Holzbach RT. Pathogenesis and medical treatment of gallstones. In: Schlesinger M, Fordtran JS (eds). Gastrointestinal Disease. $4^{\text {th }}$ edn. Philadelphia: W B Saunders; 1989. p. 1668-91.

4. Norrby S, Herlin P, Holmin T, Sjodahl R, Tagesson C. Early or delayed cholecystectomy in acute cholecystitis? A clinical trial. Br J Surg 1983;70:163-5.
5. Jarvinen HJ, Hastbacka J. Early cholecystectomy for acute cholecystitis: a prospective randomized study. Ann Surg 1980;191(4):501-5.

6. Kitano S, Matsumoto T, Aramaki M, Kawano K. Laparoscopic cholecystectomy for acute cholecystitis. J Hepatobiliary Pancreat Surg 2002; 9:534-7.

7. Bhattacharya D, Senapati PSP, Hurle R and Ammori BJ. Urgent versus interval laparoscopic cholecystectomy for acute cholecystitis: a comparative study. J Hepatobiliary Pancreat Surg 2002; 9:538-42.

8. Cuschieri A, Dubois F, Mouiel J, Mouret PB, Buess $\mathrm{G}$ et al. The European experience with laparoscopic cholecystectomy. Am J Surg 1991; 161:385-7.

9. Lai PBS, Kwong KH, Leung KL, Kwok SPY, Chan ACW, Chung SCS, et al. Randomized trial of early versus delayed laparoscopic cholecystectomy for acute cholecystitis. $\mathrm{Br} \mathrm{J}$ Surg 1998;85:764-7.

10. Kum CK, Goh PM, Isaac JR, Tekant Y, Ngoi SS. Laparoscopic cholecystectomy for acute cholecystitis. Br J Surg 1994;81:1651-4.

11. Asoglu O, Ozmen V, Karanlik H, Igci A, Kecer M, Parlak M, et al. Does the complication rate increase in laparoscopic cholecystectomy for acute cholecystitis? J Laparoendosc. Adv Surg Tech A. 2004;14(2):81-6.

12. Suter M, Meyer A. A 10-year experience with the use of laparoscopic cholecystectomy for acute cholecystitis. Surg Endosc 2001;15:118792.

13. Markus S, Lukas K, Markus WB. Predictive factors for the type of surgery in acute cholecystitis. Am J Surg 2001;182:291-7. 